\title{
National Action Plan on Breast Cancer
}

National Cancer Institute

\section{Source}

National Cancer Institute. National Action Plan on Breast Cancer. NCI Thesaurus. Code C19751.

The National Action Plan on Breast Cancer (NAPBC) is a public-private partnership created to eliminate the epidemic of breast cancer. 